\title{
The Sources and Influencing Factors of Hedonistic Consumption
}

\author{
Ying Liao \\ Jinan University, Guangzhou, China \\ Email: 353316846@qq.com
}

How to cite this paper: Liao, Y. (2021). The Sources and Influencing Factors of Hedonistic Consumption. Psychology, 12, 660-674.

https://doi.org/10.4236/psych.2021.124041

Received: April 2, 2021

Accepted: April 27, 2021

Published: April 30, 2021

Copyright $\odot 2021$ by author(s) and Scientific Research Publishing Inc. This work is licensed under the Creative Commons Attribution International License (CC BY 4.0).

http://creativecommons.org/licenses/by/4.0/

\begin{abstract}
In daily life, besides utilitarian and practical consumption, people also tend to choose hedonistic consumption that brings a variety of senses, emotions and pleasure. The sources of hedonistic product are generally explained from the aspects of the product's own attributes and individual characteristics. The influence factors of hedonistic consumption are generally explored from these two aspects. As for the consequence variables of hedonistic consumption, we find that they generally affect individual satisfaction, happiness, guilt and behavior of subsequent purchase. In the future, we can return to the origin of hedonistic consumption-happiness, and explore other research directions of hedonistic consumption from the perspective of purpose or motivation.
\end{abstract}

\section{Keywords}

Practical Consumption Hedonistic Consumption Influence Factor Consequence Variable

\section{Introduction}

With the improvement of the economic level of life and the acceleration of the current pace of life, people have entered a well-off life. On the basis of meeting the basic needs of life, people begin to choose hedonistic consumption that brings a variety of senses, emotions and pleasure.

However, according to the results of China's national physical fitness monitoring survey, the overall qualified rate of China's national physical fitness has continued to rise, and the physical health status of students has improved on the whole, but the rates of overweight and obesity among people of all ages have continued to increase. Among them, the endurance, speed, explosive power, strength quality of college students continued to decline. Overweight and obesity rates among primary and middle school students, adults, and the elderly con- 
tinue to increase. The detection rate of poor visual acuity in students continues to increase and shows a tendency of younger age. The absolute strength and explosive power of adults continue to decline. The strength quality of the elderly has been reduced.

The important reason for this result is that people choose more hedonistic consumption in their daily life, and give up practical consumption which is beneficial to their long-term interests. For example, consumers eat a lot of short-term junk food and spend a lot of time watching TV and playing computer games rather than sticking to practical physical exercise and a healthy diet.

As an emerging consumption mode, hedonistic consumption has gradually been attached importance to the marketing industry. And for consumers, we need to understand the sources and influencing factors of hedonistic consumption, so as to make better choices in consumption.

\section{Hedonistic Product}

Hedonism refers to the value concept and way of life that takes the comfort and abundance of material life and the full satisfaction of sensory desire as the purpose of life. The concept of hedonistic product corresponds to utilitarian consumption. In the process of practical consumption, consumers often start from the functional type and purpose of the product, pay attention to the utility and perform attributes of the product, and pursue the practical value to meet the actual needs. Hedonistic consumption refers to viewing consumption as an act of providing entertainment for the purpose of obtaining pleasure from consumption experience. It focuses on the emotional and irrational aspects of buying behavior.

Holbrook and Hirschman (1982) first defined hedonistic product and believed that hedonistic product is the aspect of consumption experience that includes emotion, fantasy and sense. They concluded from the four aspects of psychological construction, the product category, the product function and individual difference that hedonistic product is based on such emotions and experiences as beauty, pleasure, imagination and entertainment. Alba and Williams (2013) propose that the key to the hedonistic component is whether the individual feels pleasure when consuming the item. Pleasure comes from two sources. First, it comes from the inherent nature of the good or service. The second is the interaction in the use of goods or services, such as the pleasure of talking with others while traveling, or even the pleasure of bargaining with a salesperson when buying something. In a word, hedonistic consumption pays more attention to consumer experience and feeling.

In goal-directed point of view, compared with the utilitarian consumption to complete a task is considered as the ultimate purpose of consumption. The researchers see the hedonistic product as human-driven, and the product is only as a means to achieve the goal of pleasure. In other words, the hedonistic product is not in order to meet the actual need, the purpose of it constantly pursuing is 
manufactured, which is stimulated the desire of satisfaction. That means, what people consume is not the use value of goods or services, but their symbolic meaning. And this view is often combined with explanation level, under low explanation level, people pay more attention to the details of the things, pay attention to how to do it (Trope \& Liberman, 2010), the behavior of individuals tend to think in the near future is near to the target, so that they get the permission of slightly off target behaviors (Conway \& Peetz, 2012).

However, many consumers' behaviour is driven by some combination of pragmatic and hedonistic motives, and determining the relative strength of each can be a difficult task. A product (such as a smartphone or computer) can help users pursue both utilitarian and hedonistic goals. In addition, researchers must carefully consider the distinction between means and ends. A beautiful flowerbed may require hard work, just as satisfaction after exercise is achieved through painful effort. Instead, a properly working lawnmower (and the obligation to reuse it) can be the result of a few hours of happy tinkering. That is to say, the goal-oriented perspective may only partially explain people's misguided pursuit of it, but there is no review of literature on how hedonistic consumption arises and how it affects people's lives. So in this paper, the hedonistic product and its influence factors and the consequences of hedonistic product and variables are discussed, so that subsequent scholars can better study of hedonistic product.

\section{The Sources of Hedonistic Product}

As mentioned above, hedonistic consumption focuses on consumers' experiences and feelings, and the focus on pleasure experiences inevitably leads to some questions about what provides pleasure and what causes pleasure. The idea that some experiences are pleasurable in themselves, and more so than others, is consistent with a comparative approach that contrasts hedonistic consumption with utilitarian consumption.

After a summary of the classification of the numerous researches, we found ways to produce hedonistic consumption can be roughly divided into two kinds, one kind is commodity and events, namely the inherent attributes of objects, including the ideas embodied in goods, concern or style, or even commodity aesthetics and design sense, these properties make people more willing to choose the hedonistic product. And the other kind is the individual's subjective experience or interpretation of the commodity or event. The pleasure brought by commodity-individual interaction may be regulated by the individual characteristics of consumers, and the subjective experience will be different if each person responds differently to the characteristics of the commodity. Consumers' subjective experience of pleasure originates from consumers' psychological profile and the inherent attributes of things, that is, consumers' expectation of things and their sense of involvement in things. Many individual subjective characteristics of consumers will also affect their subjective experience, resulting in 
the tendency of hedonistic consumption, etc. (Haws \& Poynor, 2008).

\subsection{Properties of the Product Itself}

In addition to physical happiness, products with many functions bring happiness, and consumers find psychological pleasure, including but not limited to putting their own thoughts, health care, style into a product, or even the basic nature of a product can satisfy people's pursuit of a sense of reality.

One approach to happiness is based on a design perspective. Norman (2004), the most famous proponent of happy design, advocates three different levels of treatment or understanding of products and their characteristics. The inner level, however, is an intrinsic response that is primarily to the properties of physical products, a response that best fits the common understanding of aesthetic responses. The behavioral layer includes functionality, performance, and usability, while the most novel reflective layer from a design perspective includes meaning and interpretation. Each of these three layers of processing can bring pleasure in its own way, just as the pleasure users get from the iPad is not only its appeal, but also its ease of use and its futuristic feel. Similarly, Jordan (2000) proposed four kinds of product pleasures: 1) Physio-Pleasures, from the senses, 2) Socio-Pleasures, from interpersonal and group relationships, 3) Psycho-Pleasures, from one's emotional and cognitive response to product use, and 4) Ideo-Pleasures, from a broader range of product meaning and personal values.

Recently research on aesthetics in consumer decision-making has shown that consumers are concerned not only with aesthetics outside the decision-making process, but also with product categories that are not purely aesthetic (Hagtvedt \& Patrick, 2008a; Reimann, Zaichkowsky, Neuhaus, Bender, \& Weber, 2010). For example, aesthetics may not be appreciated per se, but rather through its impact on other product-related dimensions, such as the placement of artwork on a product or packaging that changes the brand's perception of luxury. Whether through art or other means, the perception of luxury goods and the resulting pleasure may be in turn lead consumers to be more cognitively tolerant, more inclined to emotion-based rather than cognition-based processing, and therefore more likely to engage in hedonistic product (Hagtvedt \& Patrick, 2008b).

In addition, hedonistic consumption responds very strongly to aesthetic characteristics, even in products that are not generally considered hedonistic products. When consumers are faced with a hedonistic choice (i.e., a product that has outstanding aesthetic and design features) but fail to meet functional criteria, and a product that has outstanding features but is less appealing, it is not surprising that the latter is favored. However, when both options exceed basic function and hedonistic needs, the hedonistic option is favored (Chitturi, Raghunathan, \& Mahajan, 2008).

The emotional response of consumers to consume is consistent. When the product meets or exceeds the utilitarian standard, the consumer experience is 
satisfied. When a product meets or exceeds hedonistic standards, consumers feel excited and happy, become more loyal, and are more inclined to positive word-of-mouth marketing (Chitturi, Raghunathan, \& Mahajan, 2008). Therefore, companies can promote hedonistic products by enhancing the aesthetic and other hedonistic qualities of their products to increase customers' sense of excitement or pleasure.

\subsection{Individual Traits}

It is well known that consumers' satisfaction with an item or experience matches their expectations of the item or experience. Wilson and Klaaren's (1992) model of emotional expectations assumes that people's emotional responses to stimuli are related to their expectations of the stimulus, so their expectations tend to determine their emotional responses. Subsequent studies have shown that once consumers have experienced a pleasuring item or experience, they are more likely to want it, including entertainment (Wilson, Lisle, Kraft, \& Wetzel, 1989), food and drink (Lee, Frederick, \& Ariely, 2006), and clothing (Hoch \& Ha,1986). So does happiness also correspond to underlying changes in feelings and perceptions? Or are consumers just happy in words, rather than actually experiencing happiness? Studies have shown that the market intervention can influence consumers' attention to different dimensions of a product, which in turn affects their evaluation of the product (Elder \& Krishna, 2010; Hoch \& Ha, 1986). In addition, this effect may extend to perceptual description (Hoegg \& Alba, 2008) and sensory enjoyment (Lee et al., 2006). In fact, recent evidence suggests that product information, such as the brand name (McClure et al., 2004) or price (Plassmann, O'Doherty, Shiv, \& Ranger, 2008) can influence happiness on a neural level, suggesting that expectations driven happiness is something that has been experienced, not just expressed.

However, from the point of view of daily consumption of pleasure, this distinction may not be so important. If consumers enjoy the experience, or when marketing raises their expectations, the experience is enjoyable, regardless of whether the sensory perception has actually changed. For example, despite not being able to distinguish between cheap wines, they still experienced greater pleasure when enjoying an expensive bottle of wine, without thinking too much about the reasons for it.

Moreover, in today's consumer society, consumption has become an object system to satisfy desires, a system of commodity code, and to acquire identity and a process of symbolic belief. When people consume, they pay attention not only to enjoy themselves, but mainly to show off their wealth, status and status. To convey a sense of social superiority and provoke envy, respect and envy. In this respect, hedonistic consumption is not about consuming the use value of goods to satisfy needs, but about consuming the symbolic value of goods to express differences. People are eager to express their own personality, taste, status through consumption, to obtain the identity, envy and praise from others. 


\section{Factors Influencing Hedonistic Product}

In the hedonistic product influence factors and practical application, researchers have made a comprehensive and in-depth discussion. Marketing scholars mostly focus on the definition of hedonistic goods and the marketing methods of specific commodities, while psychologists focus on the psychological mechanism of individual hedonistic products. With the application of experimental methods, scholars at home and abroad have explored a series of factors that affect the consumption of hedonistic goods.

\subsection{Related to Product Features}

Previous studies have been conducted on product mix, additional products, diversification of product categories, comparative presentation of products, and product discounting in consumer product selection (Simonson \& Nowlis, 2000; Strahilevitz \& Myers, 1998; Okada, 2005; Fishbach \& Zhang, 2008; Uzma et al., 2010). When there are a large number of product categories, consumers often rely on a reasonable explanation or purpose to make purchase decisions, instead of pursuing the best results. Practical goods, as consumer goods more in line with social traditions, can often provide consumers with more reasons. Therefore, faced with the bewildering product categories, consumers are more likely to choose practical products (Simonson, \& Nowlis, 2000). Similarly, when hedonistic goods are accompanied by donation (for example, 1 yuan will be donated to the disaster area for each purchase), consumers are more likely to buy them, because such donation provides consumers with reasons to consume hedonistic goods and alleviates consumers' guilt (Strahilevitz \& Myers, 1998).

In terms of product mix, when hedonistic products and practical products are presented at the same time and the competition between the two products is emphasized, consumers are more likely to provide more reasons for choosing practical products through comparison. However, when hedonistic goods and real goods are displayed separately or the competition between them is weakened, consumers are more likely to find reasons for hedonistic consumption (Okada, 2005; Fishbach \& Zhang, 2008).

In terms of promotional discounts, Kivetz's \& Simonson's (2002a) study confirmed that the lower the availability of membership discounts, the more stringent the conditions, and the more consumers are tending to strive to get hedonistic products preferential, because the effort to obtain membership discounts reduces consumers' sense of guilt for choosing hedonistic products. Since then, Uzma et al. (2010) and Kivetz \& Zheng (2017) studied the promotional discounts for consumer products, the experimental results show that when consumers are faced with mixed type product portfolio, pleasure-seeking type product discount is more able to promote the sale of the product portfolio, this is because the hedonistic products price offer consumers a reason to reasonable consumption. And the real goods' price elasticity is small, the price cuts will have little effect on the consumer choice. 
Yang et al. (2014) shifted the research focus to the Internet. Her research confirmed that arousal, questioning, remote monitoring and time distortion increased consumers' hedonistic consumption, while the sense of control, product importance, speed and consumers' acquired skills increased consumers' practical consumption. Afterwards, Zheng Hailin (2016) introduced the variable of high and low explanatory level on the basis of the research on the consumer sentiment, and verified it by experiments: in the face of real items, the purchase intention of consumers with positive emotions was higher than that of consumers with negative emotions when the high level of explanation information was emphasized, while the purchase intention of consumers with negative emotions was stronger when the low level of explanation information was emphasized. In the face of hedonistic goods, when the high level of explanation information is highlighted, consumers with positive emotions have higher purchase intention, while when the low level of explanation information is highlighted, consumers with different emotions have no difference in the purchase intention.

\subsection{Related to Consumers Themselves}

Resources at the disposal of consumers themselves (Arkes et al., 1994; Levav \& Zhu, 2009) and the decision-maker's own state (Kivetz \& Zheng, 2006; Vohs et al., 2008; Fishbach \& Dhar, 2005; Laran \& Janiszewski, 2009; Khan \& Dhar, 2006; He, 2014) will affect hedonistic products.

In terms of resources at the disposal of consumers themselves, Arkes et al. (1994) found that unexpected money was usually more likely to be spent than planned money. This "windfall" will be relegated to a new psychological account and will be more likely to be used to buy luxuries, or hedonistic purchases. Levav \& Zhu (2009) found that when a certain amount of money is acquired with negative emotions (such as the illness of a loved one), it is more likely to be spent on real goods to reduce negative emotions and feelings of guilt.

In terms of decision-makers' own state, consumers' early achievement efforts and self-control (Kivetz \& Zheng, 2006; Vohs et al., 2008), the early consumption of hedonistic products (Fishbach \& Dhar, 2005; Laran \& Janiszewski, 2009), and the positive image in public (Khan \& Dhar, 2006), which will increase consumers' hedonistic consumption. This is because consumers have a reason to "reward themselves" after the successful implementation of self-control or the realization of self-goals, which reduces the sense of guilt when choosing hedonistic goods. He Wei (2014) verified the effect of the fit between individual biological clock and experimental time on the level of individual cognitive resources, and confirmed that when the state of individual biological clock is consistent with the time of product selection, consumers are more inclined to choose practical products. Lu Jianfei et al. (2017) proved through experiments that consumers' own sense of scarcity will affect consumers' choice of real goods for enjoyment. This is because the sense of scarcity initiates the consumer's precautionary orientation. When consumers have some social support, the impact 
of perceived scarcity on consumer product selection is reduced.

\subsection{Related to the Decision-Making Process of Consumers}

Individual decision-making characteristics (Khan, 2007; Dhar \& Wertenbroch, 2000; Yuan et al., 2008; Bohm \& Pfister, 1996), Product Selection Characteristics (O'Curry \& Strahilevitz, 2001; Camerer, 1988) and decision to goal (Alexander, 2004; Maimaran \& Simonson, 2011; Chartrand, 2008) can also affect hedonistic products.

In terms of decision-making characteristics, Khan (2007) found that consumers tend to choose hedonistic goods when faced with a recent decision, because people tend to be optimistic about future expectations. Dhar \& Wertenbroch (2000) found that in order to retain positive emotions as much as possible, consumers tend to choose real products when making the decision of giving up. When the decision-making process is interrupted, consumers will change from bottom-up, data-oriented decision-making mode to top-down, goal-oriented decision-making mode (Yuan et al., 2008). Bohm \& Pfister (1996) found that consumers are more inclined to choose practical products in public places in order to conform to social norms.

In terms of the characteristics of product selection, O'Curry and Strahilevitz (2011) point out that when the acquisition of a product is uncertain, consumers tend to use it for hedonistic goods. According to the research of Camerer (1988), people are more inclined to use hedonistic goods when buying gifts to others than when buying things for themselves.

In terms of decision-making goals, Alexander (2004) has confirmed that consumers with different regulatory orientations tend to have different types of products. The consumers with profit orientation tend to choose practical products, while the consumers with harm avoidance orientation prefer hedonistic products. Maimaran \& Simonson (2011) found that when people have the goal of personal expression, they are more inclined to buy hedonistic products, because the use of hedonistic products is considered to be a behavior that can express their own taste and preferences. Later on, Chartrand (2008) further found that some subconscious goals motivated by the environment could also influence consumers' product selection.

\section{Consequences of Hedonistic Consumption}

Previous studies focused more on the influencing factors of hedonistic product, but did not summarize the consequential variables of hedonistic product. Researchers found that the happiness and satisfaction of individuals are improved after hedonistic products. But the researchers also found that compared with the practical consumption, hedonistic products are more likely to get guilt, spending a negative self-image and get high-level objectives. This leads to increased motivation to justify or justify their choices in subsequent actions (what we call "reason mindsets"), breaking the applied mindset that is motivated by the previous 
action.

\subsection{Happiness}

Leonardo et al. (2009) empirically studied the moderating effect of purchase valence on the impact of hedonistic product and practical consumption on happiness. The results show that when the purchase outcome is positive, hedonistic products produce more happiness than practical consumption. When the purchase result is negative, hedonistic product does not produce more happiness than material consumption. Guevarra \& Howell (2015) for the first time took the three basic psychological needs in the self-determination theory as the mediating path and empirically studied the impact of material consumption, life experience and hedonistic consumption on happiness. This paper not only further defines and expands the purchase types, discusses the differences in the impact of different purchase types on happiness, but also explains the reasons for the differences in happiness caused by different purchase types from the perspective of satisfying basic psychological needs.

Moreover, many scholars have shown that both hedonistic and materialistic consumption can increase happiness (Mcgregor \& Little, 1998; Ryan \& Deci, 2001). Huta and Ryan (2010) used multiple happiness measures (e.g., positive emotion, meaning, sublimation experience, etc.) to study the relationship between hedonistic motivation and actualization motivation based behavior and happiness. They found that hedonistic and achievement-based behavior had the same effect on some dimensions of happiness, but had distinct effects on others. For example, according to both intergroup and intra-group experiments, hedonistic behavior was more positively correlated with positive affective and carefree dimensions of well-being, while pragmatic behavior was more positively correlated with meaning dimensions, but both had the same effect on subjective vitality and were correlated with life satisfaction to the same extent. In the inter-group experiment, realizationism is more positively correlated with sublimation experience (Huta \& Ryan, 2010). From the perspective of hedonistic content consumption, it has been proven by scholars that watching entertainment videos can trigger strong positive emotions (Fredrickson \& Branigan, 2005), thus leading to the happiness of consumers.

\subsection{Satisfaction}

Wirtz (2003) divides products into functional products and hedonistic products, and customer satisfaction will be affected if the performance level of functional attributes and hedonistic attributes of a product is not consistent with customer expectation level. Cvejic et al. (2012) also confirmed the influence of product-related attributes on the formation of consumer attitudes. Yang Jie et al. (2011) proved through empirical research that consumers' evaluation of product attributes will affect brand attitudes and purchase intentions.

Consumers inevitably consider the utilitarian and hedonistic attributes of 
products (or services) at the same time when evaluating products. The utilitarian attribute of the product provides a rational explanation for consumers' purchasing behavior. The hedonistic property of a product can attract consumers, induce buying behavior, and bring positive emotional reaction to consumers. These two attributes of the product will have a direct impact on consumer satisfaction. Consumers are not completely rational people. If the products only pay attention to utilitarian attributes and the consumption lacks emotional experience, consumer satisfaction will be affected. If a product only focuses on the hedonistic attribute, even if some factors effectively induce consumers to buy the product, consumers will still have a feeling of guilt for buying the unpractical product, which will also affect the satisfaction level of consumers. In addition, due to the upgrading of consumers' consumption preferences, researchers have found that starting from the utilitarian attributes of products to seek the differentiation of technological quality, comfort and cost performance can only achieve half the result with double effort, and the key to improve satisfaction lies in the hedonistic attribute (Zhao, 2019).

\subsection{Guilt}

Consumers often feel guilty when they enjoy hedonistic consumption. First, with limited economic resources, spending money on hedonistic goods rather than real goods are often considered a waste (Lascu, 1991), which leads to feelings of guilt (Kivetz \& Simonson, 2002a, 2002b; Prelec \& Loewenstein, 1998; Strahilevitz \& Myers, 1998). This concept is a reflection of national, ethnic or religious culture that "appreciates thrift and opposes extravagance and waste".

Second, the benefits of hedonistic goods are harder to quantify than they are for real goods. The benefits of hedonics are primarily experiential, which is more difficult to evaluate and quantify than the benefits of physical goods in accomplishing a practical task. More objective and persuasive for quantitative reasons (Hsee, 1996; Shafir, Simonson, \& Tversky 1993), people are therefore more likely to rationalize purchases of real goods than of hedonistic ones. Unlike physical goods, consumers are more likely to feel guilt and pain about paying for hedonistic goods, and even to evoke negative self images and long-term goals (such as frugality) (Kivetz \& Simonson, 2002b; Kivetz \& Zheng, 2006; Fishbach, Freidman, \& Kruglanski, 2003).

\subsection{Subsequent Purchase Intention}

Given the choice between hedonistic consumption and practical consumption, people instinctively prefer hedonistic consumption, yet most people find it difficult to make the decision to buy or choose the hedonistic goods instead of the real ones. That's because people find it harder to justify their hedonistic product than their utilitarian consumption. If the marketing model can provide external or internal reasons to eliminate consumers' sense of guilt, it can increase the possibility of consumers buying or choosing hedonistic goods. 
Yao Qing (2012)'s study, which controls the conditions of the category of experimental stimuli, attractive possibility, purchase, price and purchase, adopting the method of real purchase. He found that after purchasing real goods, consumers are significantly more likely to purchase subsequent unrelated products, but after purchasing hedonistic goods, consumers are significantly less likely to purchase subsequent unrelated products. However, by reducing their guilt, people are more likely to opt for hedonistic consumption.

\section{Summary}

In recent years, there have been many researches on hedonistic products in the field of consumption, and many marketers and consumerists are interested in it. Starting from the definition of hedonistic consumption, this paper explores the origin of hedonistic consumption, which is generally based on the attributes of the product itself as well as individual expectations and beliefs, leading to people's willingness to choose hedonistic consumption. And explore the influence factors of hedonistic product, develop from two sources, and find that the antecedent variables of hedonistic product generally come from the characteristics of the product itself, the characteristics of consumers and the characteristics of decision-making. And, in consequence variables hedonistic product generally affects consumer's happiness and satisfaction. At the same time, carry on the hedonistic product which lets the consumer produce guilt. But changing the consumer thinking, let consumers accept this kind of thinking, which may let the consumer be more willing to choose in the subsequent purchase hedonistic products.

So this article for consumers, under the impact of hedonistic products and practical consumption, the first thing to consider is their own economic situation, not the symbolic value of goods. In other words, in order to show off to others, show the status of paying unnecessary money, especially for students. They should be sensible and have a proper view of their resources and their state of being.

For enterprises, their products can be more in line with consumers' expectations in terms of aesthetic design, paying more attention to the interaction between commodities and individuals, optimizing the combination of product attributes, maximizing consumers' satisfaction with limited resources and improving the core competitiveness of the brand. Moreover, enterprises should know how to promote the change of consumers' thinking, so that consumers can reduce their guilt and believe that their choice is right, thus improving consumers' sense of happiness and subsequent purchase intention.

Most researchers want to refocus on the nature of hedonistic products, the pleasure factor, as it exists in and out of the laboratory, and on the value of hedonistic product itself. Future research could shed more light on when, where, and why consumers find happiness in what they consume, leading us to better understand the core of happiness and humanity. 


\section{Conflicts of Interest}

The author declares no conflicts of interest regarding the publication of this paper.

\section{References}

Alba, J. W., \& Williams, E. F. (2013). Pleasure Principles: A Review of Research on Hedonic Consumption. Journal of Consumer Psychology, 23, 2-18. https://doi.org/10.1016/j.jcps.2012.07.003

Alexander, R. (2004). Selection and Uniformization in Generalized Product. Logic Journal of IGPL, 4, 125-134. https://doi.org/10.1093/jigpal/12.2.125

Arkes, H. R., Joyner, C. A., Pezzo, M. V., Nash, J. G., Siegel-Jacobs, K., \& Stone, E. (1994). The Psychology of Windfall Gains. Organizational Behavior and Human Decision Processes, 59, 331-347. https://doi.org/10.1006/obhd.1994.1063

Bohm, G., \& Pfister, H. R. (1996). Instrumental or Emotional Evaluations: What Determines Preferences? Acta Psychologica, 93, 135-148.

https://doi.org/10.1016/0001-6918(96)00017-0

Camerer, C. (1988). Gifts as Economic Signals and Social Symbols. American Journal of Sociology, 94, 180-214. https://doi.org/10.1086/228946

Chartrand, T. L. (2008). The Role of Conscious Awareness in Consumer Behavior. Journal of Consumer Psychology, 15, 203-210. https://doi.org/10.1207/s15327663jcp1503 4

Chitturi, R., Raghunathan, R., \& Mahajan, V. (2008). Delight by Design: The Role of Hedonic versus Utilitarian Benefits. Journal of Marketing, 72, 48-63.

https://doi.org/10.1509/JMKG.72.3.048

Conway, P., \& Peetz, J. (2012). When Does Feeling Moral Actually Make You a Better Person? Conceptual Abstraction Moderates Whether Past Moral Deeds Motivate Consistency or Compensatory Behavior. Personality and Social Psychology Bulletin, 38, 907-919. https://doi.org/10.1177/0146167212442394

Cvejic, E., Kim, J., \& Davis, C. (2012). Recognizing Prosody across Modalities, Face Areas and Speakers: Examining Perceivers' Sensitivity to Variable Realizations of Visual Prosody. Cognition, 122, 442-453. https://doi.org/10.1016/j.cognition.2011.11.013

Dhar, R., \& Wertenbroch, K. (2000). Consumer Choice between Hedonic and Utilitarian Goods. Journal of Marketing Research, 37, 60-71. https://doi.org/10.1509/jmkr.37.1.60.18718

Elder, R. S., \& Krishna, A. (2010). The Effects of Advertising Copy on Sensory Thoughts and Perceived Taste. Journal of Consumer Research, 36, 748-756. https://doi.org/10.1086/605327

Fishbach, A., \& Dhar, R. (2005). Goals as Excuses or Guides: The Liberating Effect of Perceived Goal Progress on Choice. Journal of Consumer Research, 32, 370-377. https://doi.org/10.1086/497548

Fishbach, A., \& Zhang, Y. (2008). Together or Apart: When Goals and Temptations Complement versus Compete. Journal of Personality and Social Psychology, 94, 547-559. https://doi.org/10.1037/0022-3514.94.4.547

Fishbach, A., Friedman, R. S., \& Kruglanski, A. W. (2003). Leading Us Not into Temptation: Momentary Allurements Elicit Overriding Goal Activation. Journal of Personality and Social Psychology, 84, 296-309. https://doi.org/10.1037/0022-3514.84.2.296

Fredrickson, B. L., \& Branigan, C. (2005). Positive Emotions Broaden the Scope of Attention and Thought-Action Repertoires. Cognition and Emotion, 19, 313-332. 
https://doi.org/10.1080/02699930441000238

Guevarra, D. A., \& Howell, R. T. (2015). To Have in Order to Do: Exploring the Effects of Consuming Experiential Products on Well-Being. Journal of Consumer Psychology, 25, 28-41. https://doi.org/10.1016/j.j.jps.2014.06.006

Hagtvedt, H., \& Patrick, V. M. (2008a). Art Infusion: The Influence of Visual Art on the Perception and Evaluation of Consumer Products. Journal of Marketing Research, 45, 379-389. https://doi.org/10.1509/jmkr.45.3.379

Hagtvedt, H., \& Patrick, V. M. (2008b). Art and the Brand: The Role of Visual Art in Enhancing Brand Extendibility. Journal of Consumer Psychology, 18, 212-222.

https://doi.org/10.1016/j.jcps.2008.04.010

Haws, K. L., \& Poynor, C. (2008). Seize the Day! Encouraging Indulgence for the Hyperopic Consumer. Journal of Consumer Research, 35, 680-691.

https://doi.org/10.1086/592129

He, W. (2014). The Effect Study of Circadian Rhythm and Test Time to the Choice Making between Hedonic and Utilitarian Goods. M.A. Thesis, Chengdu: Southwestern University of Finance and Economics.

Hoch, S. J., \& Ha, Y. W. (1986). Consumer Learning: Advertising and the Ambiguity of Product Experience. Journal of Consumer Research, 13, 221-233. https://doi.org/10.1086/209062

Hoegg, J., \& Alba, J. W. (2008). A Role for Aesthetics in Consumer Psychology. In C. P. Haugtvedt, P. M. Herr, \& F. R. Kardes (Eds.), Marketing and Consumer Psychology Series: Vol. 4. Handbook of Consumer Psychology (pp. 733-754). London: Taylor \& Francis Group/Lawrence Erlbaum Associates.

Holbrook, M. B., \& Hirschman, E. C. (1982). The Experiential Aspects of Consumption: Consumer Fantasies, Feelings, and Fun. Journal of Consumer Research, 9, 132-140. https://doi.org/10.1086/208906

Hsee, C. K. (1996). The Evaluability Hypothesis: An Explanation for Preference Reversals between Joint and Separate Evaluations of Alternatives. Organizational Behavior and Human Decision Processes, 67, 247-257. https://doi.org/10.1006/obhd.1996.0077

Huta, V., \& Ryan, R. M. (2010). Pursuing Pleasure or Virtue: The Differential and Overlapping Well-Being Benefits of Hedonic and Eudaimonic Motives. Journal of Happiness Studies, 11, 735-762. https://doi.org/10.1007/s10902-009-9171-4

Jordan, P. W. (2000). Designing Pleasurable Products: An Introduction to the New Human Factors. London: Routledge. https://doi.org/10.4324/9780203305683

Khan, M. A. (2007). Consumer Behaviour and Advertising Management. Delhi: New Age International.

Khan, U., \& Dhar, R. (2006). Licensing Effect in Consumer Choice. Journal of Marketing Research, 43, 259-266. https://doi.org/10.1509/jmkr.43.2.259

Kivetz, R., \& Simonson, I. (2002a). Earning the Right to Indulge: Effort as a Determinant of Customer Preferences toward Frequency Program Rewards. Journal of Marketing Research, 39, 155-170. https://doi.org/10.1509/jmkr.39.2.155.19084

Kivetz, R., \& Simonson, I. (2002b). Self-Control for the Righteous: Toward a Theory of Precommitment to Indulgence. Journal of Consumer Research, 29, 199-217. https://doi.org/10.1086/341571

Kivetz, R., \& Zheng, Y. (2006). Determinants of Justification and Self-Control. Journal of Experimental Psychology: General, 135, 572-587. https://doi.org/10.1037/0096-3445.135.4.572

Kivetz, R., \& Zheng, Y. (2017). The Effects of Promotions on Hedonic versus Utilitarian 
Purchases. Journal of Consumer Psychology, 27, 59-68.

https://doi.org/10.1016/j.jcps.2016.05.005

Laran, J., \& Janiszewski, C. (2009). Behavioral Consistency and Inconsistency in the Resolution of Goal Conflict. Journal of Consumer Research, 35, 967-984.

https://doi.org/10.1086/593293

Lascu, D. N. (1991). Consumer Guilt: Examining the Potential of a New Marketing Construct. Advances in Consumer Research, 18, 290-295.

Lee, L., Frederick, S., \& Ariely, D. (2006). Try It, You'll Like It: The Influence of Expectation, Consumption, and Revelation on Preferences for Beer. Psychological Science, 17, 1054-1058. https://doi.org/10.1111/j.1467-9280.2006.01829.x

Leonardo, N., Julie, R. L., \& Joseph, K. G. (2009). Happiness for Sale: Do Experiential Purchases Make Consumers Happier than Material Purchases? Journal of Consumer Research, 36, 188-198. https://doi.org/10.1086/597049

Levav, J., \& Zhu, R. (2009). Seeking Freedom through Variety. Journal of Consumer Research, 36, 600-610. https://doi.org/10.1086/599556

Lu, J. F., Li, Z. L., \& Jiang, L. (2017). The Sense of Scarcity Affects Consumers' Choice of Real Products Study on Influencing Mechanism-Based on the Perspective of Regulatory Orientation Theory. Dongyue Review, 38, 153-162.

Maimaran, M., \& Simonson, I. (2011). Multiple Routes to Self- versus Other-Expression in Consumer Choice. Journal of Marketing Research, 48, 755-766.

https://doi.org/10.1509/jmkr.48.4.755

McClure, S. M., Li, J., Tomlin, D., Cypert, K. S., Montague, L. M., \& Montague, P. R. (2004). Neural Correlates of Behavioral Preference for Culturally Familiar Drinks. Neuron, 44, 379-387. https://doi.org/10.1016/j.neuron.2004.09.019

Mcgregor, L., \& Little, B. R. (1998). Personal Projects, Happiness, and Meaning: On Doing Well and Being Yourself. Journal of Personality and Social Psychology, 74, 494-512. https://doi.org/10.1037/0022-3514.74.2.494

Norman, D. A. (2004). Emotional Design. New York: Perseus. https://doi.org/10.1145/966012.966013

O'curry, S., \& Strahilevitz, M. (2001). Probability and Mode of Acquisition Effects on Choices between Hedonic and Utilitarian Options. Marketing Letters, 12, 37-49. https://doi.org/10.1023/A:1008115902904

Okada, E. M. (2005). Justification Effects on Consumer Choice of Hedonic and Utilitarian Goods. Journal of Marketing Research, 42, 43-53. https://doi.org/10.1509/jmkr.42.1.43.56889

Plassmann, H., O’Doherty, J., Shiv, B., \& Rangel, A. (2008). Marketing Actions Can Modulate Neural Representations of Experienced Pleasantness. Proceedings of the National Academy of Sciences, 105, 1050-1054. https://doi.org/10.1073/pnas.0706929105

Prelec, D., \& Loewenstein, G. (1998). The Red and the Black: Mental Accounting of Savings and Debt. Marketing Science, 17, 4-28. https://doi.org/10.1287/mksc.17.1.4

Reimann, M., Zaichkowsky, J., Neuhaus, C., Bender, R., \& Weber, B. (2010). Aesthetic Package Design: A Behavioral, Neural, and Psychological Investigation. Journal of Consumer Psychology, 20, 431-441. https://doi.org/10.1016/j.jcps.2010.06.009

Ryan, R. M., \& Deci, E. L. (2001). On Happiness and Human Potentials: A Review of Research on Hedonic and Eudaimonic Well-Being. Annual Review of Psychology, 52, 141-166. https://doi.org/10.1146/annurev.psych.52.1.141

Shafir, E., Simonson, L., \& Tversky, A. (1993). Reason-Based Choice. Cognition, 49, 11-36. https://doi.org/10.1016/0010-0277(93)90034-S 
Simonson, I., \& Nowlis, S. M. (2000). The Role of Explanations and Need for Uniqueness in Consumer Decision Making: Unconventional Choices Based on Reasons. Journal of Consumer Research, 27, 49-68. https://doi.org/10.1086/314308

Strahilevitz, M., \& Myers, J. G. (1998). Donations to Charity as Purchase Incentives: How Well They Work May Depend on What You Are Trying to Sell. Journal of Consumer Research, 24, 434-446. https://doi.org/10.1086/209519

Trope, Y., \& Liberman, N. (2010). Construal-Level Theory of Psychological Distance. Psychological Review, 117, 440. https://doi.org/10.1037/a0018963

Uzma, S. H., Singh, J. P., \& Kumar, N. (2010). Discounted Cash Flow and Its Implication on Intangible Valuation. Global Business Review, 11, 365-377. https://doi.org/10.1177/097215091001100304

Vohs, K. D., Mead, N. L., \& Goode, M. R. (2008). Merely Activating the Concept of Money Changes Personal and Interpersonal Behavior. Current Directions in Psychological Science, 17, 208-212. https://doi.org/10.1111/j.1467-8721.2008.00576.x

Wilson, T. D., \& Klaaren, K. J. (1992). “Expectation Whirls Me Round”: The Role of Affective Expectations on Affective Experience. In M. S. Clark (Ed.), Review of Personality and Social Psychology: Emotion and Social Behavior (Vol. 14, pp. 1-31). Newbury Park, CA: Sage.

Wilson, T. D., Lisle, D. J., Kraft, D., \& Wetzel, C. G. (1989). Preferences as Expectation-Driven Inferences: Effects of Affective Expectations on Affective Experience. Journal of Personality and Social Psychology, 56, 519. https://doi.org/10.1037/0022-3514.56.4.519

Wirtz, J. (2003). Halo in Customer Satisfaction Measures. International Journal of Service Industry Management, 14, 96-119. https://doi.org/10.1108/09564230310466001

Yang, J., Zeng, X. H., \& Gu, Y. K. (2011). The Influence of Country (Region) Image and Product Attribute on Brand Attitude and Purchase Intention. Business Economic, 9, 51-53.

Yang, M. H., Weng, S. S., \& Hsiao, P. I. (2014). Measuring Blog Service Innovation in Social Media Services. Internet Research, 24, 110-128. https://doi.org/10.1108/IntR-12-2012-0253

Yao, Q. (2012). The Different Influences of Hedonic versus Utilitarian Purchase on the Subsequent Purchase Behavior. M.A. Thesis, Beijing: Tsinghua University.

Yuan, X., Dou, Z., Zhang, L., \& Liu, F. (2008). Automatic User Goals Identification Based on Anchor Text and Click-Through Data. Wuhan University Journal of Natural Sciences, 13, 495-500. https://doi.org/10.1007/s11859-008-0423-7

Zhao. L. (2019). Empirical Study on the Influence of Hedonistic Attribute and Utilitarian Attribute on Consumer Satisfaction of Women's Wear. M.A. Thesis, Qingdao: Qingdao University.

Zheng, H. L. (2016). The Influence of Emotion and Product Types on the College Students' Preference of Products-Perspective of Construal Level. M.A. Thesis, Nanchang: Jiangxi Normal University. 